\title{
THE DEVELOPMENT AND PILOTING OF AN INSTRUMENT TO MEASURE NATURE OF SCIENCE (NOS) UNDERSTANDING
}

\author{
Tarisai Chanetsa, \& Umesh Ramnarain \\ Department of Science and Technology Education, University of Johannesburg (South Africa)
}

\begin{abstract}
The study describes the development of an instrument, to measure NOS understandings of science teachers and a subsequent pilot study to test the instrument. The pilot measured NOS understanding of two teachers using a questionnaire that had been developed by the researcher. The objective of the study was to construct a questionnaire that could measure NOS understanding based on the family resemblance approach (FRA). The NOS is a construct that has been defined by various scholars and there exists multiple perspectives. For this study, two schools of thought defining the nature of science: the consensus view (CV) and the reconceptualized family resemblance approach to NOS (RFN) were considered. The CV has been widely accepted for years to represent the NOS through its tenets, and there exists reliable tools to document NOS. Based on the CV researchers developed an instrument, views of nature of science (VNOS), to document NOS understanding. In the past decade, scholars have challenged the CV of NOS and highlighted shortcomings in its tenets. FRA was developed that depicts science in a holistic system with dynamic interactions unlike the CV that represents NOS as independent tenets. From FRA, emerged RFN consisting of social and cultural categories that affect how science is done. The approach of RFN due to its holistic approach will be preferred in this study. The authors of RFN developed a RFN questionnaire to assess views about NOS using a Likert scale. Due to the limitations of the Likert scale, an open-ended approach is preferred in the qualitative analysis of views of NOS as is found in the VNOS form. To collect data on NOS understanding, the researcher compared VNOS and the RFN questionnaire and developed an integrated family VNOS (IFVNOS) questionnaire.

The IFVNOS questionnaire was administered in a pilot test followed by interviews to elaborate on responses. The responses were analysed by two coders and triangulated to ensure reliability. The responses were allocated codes to document NOS understanding, on a range from naïve to explicit understanding. The findings revealed that the IFVNOS questionnaire developed can be used as a tool to measure NOS understanding and more testing is required to assess reliability.
\end{abstract}

Keywords: Views, nature, science, family resemblance.

\section{Introduction}

This paper describes the development of an instrument to measure nature of science (NOS) understandings of science teachers and a subsequent pilot study to test the instrument. The NOS is a construct that has been defined by various scholars and there exists multiple perspectives. For this study, two schools of thought defining the nature of science: the consensus view by Abd-El-Khalick (2013) and the reconceptualized family resemblance approach to NOS (RFN) by Erduran and Dagher (2014) were considered. Based on these two schools of thought, the researcher developed an analytical framework, the integrated family views of nature of science (IFVNOS) and developed a questionnaire to assess views of NOS based on IFVNOS. The aims of the study are listed below.

\subsection{Aims}

- To design an instrument to measure views of NOS based on the consensus view and reconceptualised family resemblance approach to NOS

- To pilot the use of the instrument to measure views of NOS of in-service science teachers

\section{The Nature of science (NOS)}

Research shows that the nature of science (NOS) is a concept that is naively understood globally. Akerson, Abd-El-Khalick, and Lederman (2000) have shown that regardless of level of education, there is an international inadequate realization of what NOS is. The misconceptions of NOS could possibly be due to the fact that there does not exist one explicit definition of what NOS is. Rather it is a concoction of 
attributes and a combination of at least seven aspects as defined by Lederman (1998) known as the tenets of NOS, such as empirical; inferential; creative; theory-driven and tentative to name a few.

These tenets are widely accepted to be a representation of the consensus view of NOS and have been used as the framework for analysing NOS pedagogical views in students and teachers by Kruse, Easter, Edgerly, Seebach, and Patel (2017); and for the analysis of curriculum documents worldwide as conducted by Lederman (2007) to name but a few. Reliable and valid instruments for NOS analysis based on the consensus view have been developed and used by researchers over decades of years such as the views of nature of science questionnaire (VNOS) developed by Lederman, Abd-El-Khalick, Bell, and Schwartz (2002). It is for this reason of reliability and validity that the consensus view will contribute to formulating the framework used to analyse views of NOS in this study.

In more recent times, scholars have challenged the consensus view of NOS and highlighted shortcomings in its tenets as not encompassing economic, political, philosophical, social and financial systems of science as stated by Erduran and Dagher (2014). The family resemblance approach to science (FRA) has been developed to depict science in a holistic system with dynamic interactions. This view of science by Irzik and Nola (2010) adopted the generic definition of family resemblance coined by Wittgenstein in 1958. They proposed four categories of the FRA that reflect NOS as a) activities b) aims and values c) methodologies and methodological rules and d) products, which they substantiated had none of the shortcomings of the consensus view of NOS. Dagher and Erduran (2016) added categories of 'social organisations and interactions', 'political power structures' and 'financial systems' to FRA. This addition was made to highlight that science is impacted by societal and cultural factors. The FRA has a number of authors but the work of Erduran and Dagher (2014) will be considered in this study as their terminology appeals to science education and are applicable for science curriculum. RFN defines NOS using categories of aims and values; methods; scientific practices; scientific knowledge; social certification and dissemination; scientific ethos; social values; professional activities; social organisations and interactions; financial systems; and political power structures.

\section{Conceptual framework}

In designing the integrated aspects of NOS conceptual framework, the researcher analysed both the consensus view tenets and RFN categories. Ideally, the framework to be used in this study should comprise explicit statements such as those in the consensus view as the researcher has found these to be user friendly in content analysis of textbooks. This study forms part of a larger research aimed at improving NOS understanding amongst teachers through the use of textbook analysis. It was found that the consensus view makes use of explicit tenets descriptive of independent NOS aspects, whilst RFN represents a holistic interactive dynamic system of NOS categories. Research in RFN is limited and not widely spread at the time of writing this paper. There is, however, sufficient evidence and reliable sources to validate the use of its instruments in science education. Studies have been carried out in pre-service teacher education courses on NOS in Turkey using the RFN approach by Kaya, Erduran, Aksoz, and Akgun (2019) and findings from this study have contributed to the understanding of how NOS can be incorporated in science teacher education using RFN. The application of RFN to curriculum analysis is not widely spread at this time but has been used in analysing the content of USA and Turkey curricular by Kaya and Erduran (2016). FRA has also been used in investigating coherence about NOS in science curriculum documents of Taiwan as was conducted by Yeh, Erduran, and Hsu (2019).

The researcher has found that within RFN categories, tenets of the consensus view on NOS are embedded. In analysing RFN the researcher found that two categories of RFN have no consensus view tenet representation, that is in the scientific ethos category and social values category. These are defined as the norms that scientists employ in their work as well as in interaction with colleagues and values such as freedom, respect for the environment and social utility respectively. In the framework that is to be developed, it is necessary to represent these two RFN categories using keywords in order to match the format of the consensus view. Keyword analysis is the approach used by the authors of RFN, Kaya and Erduran (2016) when they conducted content analysis of Turkish curriculum statements. Keyword analysis involves the selection of indicative words from the descriptors of categories. For instance, to analyse the social certification and dissemination category, Kaya and Erduran (2016) used the words provided in the description of the category. The category is defined as the social mechanisms through which scientists review, evaluate and validate scientific information through, for example, the peer review systems of journals. Kaya and Erduran (2016) selected keywords such as "peer-review", "validate", "evaluation", as the representative words of the category. From the two categories of scientific ethos and scientific values not represented in the consensus view, the researcher developed the keywords "ethical practices" derived from the definitions provided by the two categories. Ethical practices as keywords have thus been included in the conceptual framework for this study. This framework has been termed the Integrated Family Views Nature of Science (IFVNOS) and comprises (from the CV tenets): empirical, inferential, creativity, tentative, theory-driven, methods, scientific knowledge, social dimension of science, social and cultural embeddedness of science, science vs pseudoscience and derived from RFN, ethical practices. 


\subsection{IFVNOS questionnaire}

To collect views of NOS of the participant teachers, the researcher made use of the views of nature of science questionnaire version C (VNOS C) developed by Lederman et al. (2002). VNOS (C) has been validated by its authors and there exists a high level of confidence in it thus making it an instrument of choice in this research. It has undergone an intensive validation process and revisions from VNOS (A) to VNOS (B) to this version of VNOS (C). The authors have provided crucial logistical and conceptual issues for consideration by researchers using VNOS $(\mathrm{C})$ to ensure its correct administration. The issues to be aware of input into increasing the validity of the research process by ensuring correct use of the instrument with minimal errors. VNOS(C) although valid and verified had shortcomings identified by the researcher because of its basis solely on the consensus view. The need then arose to incorporate aspects of the family resemblance approach into $\operatorname{VNOS}(\mathrm{C})$ that were found to be lacking in the consensus view.

The authors of RFN Kaya at al. (2019) developed a questionnaire to assess views about NOS reflecting the five RFN categories and incorporated into the questionnaire educational applications. The RFN questionnaire comprises seventy questions with five options of responses which are 'totally agree', 'agree', 'not sure', 'disagree', and 'totally disagree' from which respondents select one option. One of the limitations of this 5-Likert scale is that the opinion and alternative responses of the respondents is not captured. Kaya et al. (2019) acknowledge the oversimplification of the instrument for the nature of data to be collected and argue that their interest was in developing an instrument for RFN. In view of this oversimplification as noted above the author of this research opted for open ended questions extracted from the $\operatorname{VNOS}(\mathrm{C})$ questionnaire, numbers 1-9 below. Questions relating to family resemblance that were not represented in $\operatorname{VNOS}(\mathrm{C})$ were added to the questionnaire, numbers 10-12 below. This formed the integrated family views of nature of science (IFVNOS) questionnaire.

1. What, in your view, is science? What makes science (or a scientific discipline such as physics, biology, etc.) different from other disciplines of inquiry (e.g., religion, philosophy)?

2. Do all scientific disciplines such as physics, astronomy, biology and chemistry use the same scientific method? Explain your answer

3. Define what an experiment is. Does the development of scientific knowledge require experiments?

If yes, explain why. Give an example to defend your position. If no, explain why. Give an example to defend your position.

4. After scientists have developed a scientific theory (e.g., atomic theory, evolution theory), does the theory ever change? If you believe that scientific theories do not change, explain why. Defend your answer with examples. If you do believe that scientific theories do change: a) explain why theories change? b) explain why we bother to learn scientific theories? Defend your answer with examples.

5. Describe the purpose of theories, laws and models in producing scientific knowledge

6. Science textbooks often represent the atom as a central nucleus composed of protons (positively charged particles) and neutrons (neutral particles) with electrons (negatively charged particles) orbiting that nucleus. How certain are scientists about the structure of the atom? What specific evidence do you think scientists used to determine what an atom looks like?

7. Scientists perform experiments or investigations when trying to find answers to the questions they put forth. Do scientists use their creativity and imagination during their investigations? If yes, then at which stage of the investigations do you believe scientists use their imagination and creativity: planning and designing, data collection, after data collection? Please explain why scientists use creativity and imagination during their investigations. If you believe that scientists do not use imagination and creativity, please explain why. Provide examples if appropriate.

8. It is believed that about 65 million years ago the dinosaurs became extinct. Of the hypotheses formulated by scientists to explain the extinction, two enjoy wide support. The first, formulated by one group of scientists, suggests that a huge meteorite hit the earth 65 million years ago and led to a series of events that led to the extinction. The second hypothesis, formulated by a second group of scientists, suggests that massive and giant volcanic eruptions were responsible for the extinction. How are these different conclusions possible if scientists in both groups have access to and use the same set of data to derive their conclusions?

9. Some claim that science is infused with social and cultural values. That is, science reflects the social and political values, philosophical assumptions, and intellectual norms of the culture it is practiced. Others claim that science is universal. That is, science transcends national and cultural boundaries and it is not affected by social, political and philosophical values and intellectual norms of the culture in which it is practiced. If you believe that science reflects social and cultural values, explain why. Defend your answer with examples. If you believe that science is universal, explain why. Defend your answer with examples.

10. Scientists engage in professional activities such as attending conferences and doing publication reviews. Why do scientists engage in such activities?

11. Scientists work in organisations or establishments such as universities and research centers, how are they organized in these institutions? 
12. Teaching epistemic, cognitive, social and cultural values should be core components of the science curriculum. Do you agree or disagree with this statement? Provide a reason for your opinion.

\section{Methodology}

The pilot study to test the IFVNOS questionnaire and its readability, adopted a structural content analysis approach. Two participant teachers were purposefully selected based on availability, access to online teaching of either natural sciences, life sciences or physical sciences. Teachers were required to complete the IFVNOS questionnaire online. On receipt of each questionnaire, the researcher drafted an interview schedule aimed at clarifying aspects of the respondents ' answers that may not have been clear or were posing conflicting messages to an understanding of NOS aspects.

\subsection{Content analysis}

"Content analysis has been defined as a systematic replicable technique for compressing many words of text (or other meaningful matter) into fewer categories based on explicit rules of coding" (Krippendorff, 1980). The qualitative data collected from IFVNOS questionnaire and the interview for each teacher were coded for NOS aspects following Saldana`s coding techniques. According to Saldana (2009) a code serves to summarize or condense data rather than simply reducing it. NOS aspects were assigned to every response provided by participants, in some instances responses comprised more than one NOS aspect. IFVNOS responses and interview responses were assigned NOS aspects independently. The units of similar NOS aspects were then grouped together for analysis to allocate a rating describing the degree of explicitness or implicitness of the NOS representation.

\subsection{Scoring rubric}

Points are allocated by the researcher from a scale of positive three points, explicit representation, to negative three points, explicit naïve representation, based on Abd El-Khalick's scoring rubric (2013). A cumulative score ranging from -33 to +33 is then assigned to the NOS understanding of each teacher. The higher the cumulative score, the more explicit, informed and consistent is the representation of NOS.

\subsection{Reliability and validity}

To ensure reliability in content analysis, Abd-El-Khalick (2013) stipulates the use of more than one rater to achieve inter rater reliability of the findings. Two raters were used in this study and each one reviewed and analysed the data independently, assigning scores of NOS understanding to the units of analysis. There was complete agreement between the findings of the two raters indicating a high level of reliability of the findings. Conducting an interview post evaluation of IFVNOS responses and triangulation of findings from both questionnaires contributed to some level of validity in the findings.

\section{Findings}

The in-service science teachers were found to have an inadequate overall understanding of the nature of science. The cumulative possible score of NOS understanding of +33 represents an explicit and informed understanding. Although the teachers in some instances displayed an explicit, informed understanding of some NOS aspects, these scores were lowered by mixed understanding or naive understanding in other instances. The table below displays some quotations from teacher responses and corresponding scores allocated by the researcher.

Table 1. Excerpts of NOS responses of teachers and score assigned.

\begin{tabular}{|l|l|l|l|}
\hline Teacher & $\begin{array}{l}\text { Cumulative } \\
\text { score } \mathbf{3 3}\end{array}$ & Example of excerpts & $\begin{array}{l}\text { NOS } \\
\text { understanding }\end{array}$ \\
\hline $\begin{array}{l}\text { Physical } \\
\text { Sciences }\end{array}$ & +13 & $\begin{array}{l}\text { Scientific theories: "Theories do change, theories are developed on } \\
\text { knowledge that are known, but often limited. Theories cannot always } \\
\text { be proven wrong, but they can't be proven right either. The lack of } \\
\text { concrete evidence proving a theory right, means that a theory can } \\
\text { change. } \\
\text { Certain models have been adapted and changed, but older models can } \\
\text { be useful to explain certain aspects" }\end{array}$ & $\begin{array}{l}\text { explicit, } \\
\text { informed }\end{array}$ \\
\hline
\end{tabular}

\section{Discussion of findings}

The inadequate NOS understanding of the teachers is commensurate with findings by Govender and Zulu (2017) in the South African context. The small number of teachers used in the pilot does not provide enough indicative findings on the reliability of the instrument. The aim of the pilot was to test if 
IFVNOS can be used to capture views of NOS and this was achieved. IFVNOS will be used on a larger number of teachers forming part of a study to improve NOS understanding through textbook analysis and the reliability of the instrument can then be commented on.

\section{Conclusion}

This paper reported on the development of an instrument to measure views of NOS that merged the consensus view and RFN. The IFVNOS questionnaire was tested on two teachers to produce findings that are commensurate with results by other researchers, that the NOS is one that is naively understood by teachers in South Africa as found by Gwebu (2015), Govender and Zulu (2017). It can be concluded from the findings of the pilot that the IFVNOS questionnaire can be used to measure NOS understanding and that there is still a need for professional development programs to improve the NOS understanding of in-service teachers.

\section{References}

Abd-El-Khalick, F. (2013). Coding and scoring instructions. Nature of science textbook analysis methods.

Abd-El-Khalick, F. (2013). Target nature of science aspects. Nature of science textbook analysis methods, $1-2$.

Akerson, V. L., \& Abd-El-Khalick, F., \& Lederman, N. G. (2000). Influence of a reflective explicit activity based approach on elementary teachers' conceptions on nature of science. Journal Research of Science Teachers, 34(7), 673-699.

Bantwini, B., \& Kurup, R., \& Linneman, S. R., \& Lynch, P., \& Webb, P. (2003). South African science teachers 'perception on the nature of science. African Journal of Research in SMT Education, 7, 35-50.

Dagher, Z. R., \& Erduran, S. (2016). Reconceptualizing the nature of science for science education. Why does it matter? Science and education, 25, 147-164. doi:10.1007/s11191-015-9800-8

Erduran, S., \& Dagher, Z. (2014). Family resemblance approach to characterizing science. Reconceptualizing the nature of science for science education (pp. 19-40). Netherlands: Springer.

Govender, G., \& Zulu, D. (2017). Natural sciences junior high school teachers` understanding of the nature of science and its impact on their planning of lessons. Journal of Baltic Science Education, 16(3), 366-378.

Gwebu, M. I. (2012). The understanding of the nature of science among physical sciences teachers from the Badplaas circuit of the Mpumalanga Province (Master's thesis, University of Johannesburg, Johannesburg, South Africa). Retrieved from https://ujcontent.uj.ac.za/vital/access/manager/ Index?site_name=Research $\% 20$ Output

Irzik, G., \& Nola, R. (2010). A family resemblance approach to the nature of science for science education. Science and Education, 20(7), 591-607.

Kaya, E., \& Erduran, S. (2016). From FRA to RFN, or How the family resemblance approach can be transformed for curriculum analysis on nature of science. Science \& Education, 25, 1115-1133.

Kaya, E., \& Erduran, S., \& Aksoz, B., \& Akgun, S. (2019). Reconceptualised family resemblance approach to nature of science in pre-service science teacher education. International Journal of Science Education, 41(1), 21-47.

Krippendorff, K. (1980). Content analysis: An introduction to its methodology (2nd ed.). Thousand Oaks, CA: Sage.

Kruse, J.W., \& Easter, J.M., \& Edgerly, H.S., \& Seebach, C., \& Patel, N. (2017). The impact of a course on nature of science pedagogical views and rationales comparing preservice teachers in their first versus second experience. Science and Education, 26, 613-636. doi:10.1007/s11191-017-9916-0

Lederman, N. G., \& Abd-El-Khalick, F., \& Bell, R. L., \& Schwartz, R. S. (2002). Views of nature of science questionnaire: toward valid and meaningful assessment of learners`conceptions of nature of science. Journal of Research in Science Teaching, 39(6), 497-521.

Saldana, J. (2009). The coding manual for qualitative researchers. An Introduction to Codes and Coding (pp. 1-31). London: SAGE Publications.

Yeh, Y., \& Erduran, S., \& Hsu, Y. (2019). Investigating Coherence About Nature of Science in Science Curriculum Documents. Science \& Education, 28, 1-20. 